\title{
UTILIZAÇÃO DE UM VEÍCULO ELÉTRICO PARA ABASTECER UMA RESIDÊNCIA NO
}

\section{HORÁRIO DE PONTA}

\section{Resumo}

Com uma tarifa horária diferenciada, o preço da energia elétrica é mais barato durante a madrugada, nos chamados horários de vazio, e mais caro no final da tarde, no horário de ponta. Uma possibilidade para evitar esse custo maior é a de se comprar a energia durante o horário de vazio, armazenála numa bateria e devolvê-la à rede no horário de ponta. $O$ presente trabalho apresenta um estudo sobre a viabilidade económica da utilização da energia disponível na bateria de um veículo elétrico para abastecer uma residência durante o horário de ponta.

\section{Introdução}

Modalidade tarifária é o conjunto de tarifas aplicáveis ao consumo de energia elétrica e procura de potência ativa, podendo ser divididas em tarifas convencionais e tarifas horárias [1].

Na primeira, o cliente é cobrado igualmente pela energia elétrica que consome independente do horário do dia ou período do ano. Já a cobrança de energia elétrica nas tarifas horárias é caracterizada por refletir os custos de outras variáveis, como o período do dia que o consumo ocorre e custo de produção.

Quando comparado um horário de ponta a um mesmo período fora da ponta, o custo de energia elétrica e da procura pode chegar até nove vezes mais que o seu corresponde num horário normal [1]. Como alternativa, a produção independente de energia elétrica pode ser um sistema economicamente viável.

Com uma capacidade assinalável nas suas baterias, os veículos elétricos (VE) podem ser utilizados como dispositivos armazenadores de energia num sistema de compensação de consumo no horário de ponta.
Isso pode ser útil também para compensar a natureza intermitente das fontes renováveis de energia, por exemplo.

\section{Sistema tarifário português}

Assim como o Brasil, Portugal possui diferentes modalidades tarifárias. Há as Tarifas de Média Tensão (MT), Baixa Tensão Especial (BTE) e a Baixa Tensão Normal (BTN) que é utilizada pela maioria dos clientes residenciais, foco deste estudo.

Para BTN, adotam-se diferentes tarifas ao longo do dia, a Ponta, a Cheia e o Vazio.

A figura 1 exemplifica visualmente a divisão horária de um dia de acordo com a respetiva tarifa.

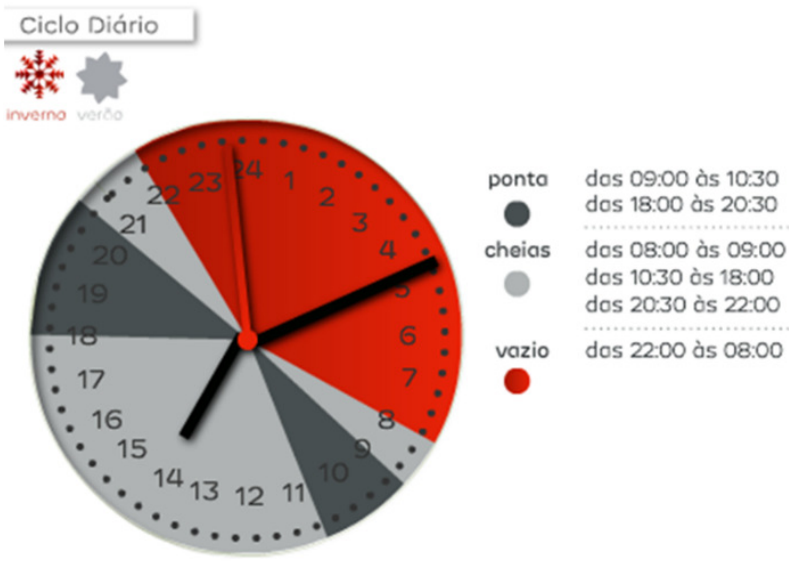

Figura 1. Divisão diária por posto tarifário [2]

Através da Equação 1 será feito o cálculo da chamada Tarifa de Compensação, pois considerar-se-á o carregamento do veículo elétrico durante a madrugada, ou horário de vazio, e sua descarga no horário de ponta.

O cálculo da economia se dará a partir da diferença entre as tarifas de compra.

Tarifa $a_{\text {compensação }}=$ Tarifa $a_{\text {ponta }}-$ Tarif $a_{\text {vazio }}$ 


\section{Veículos elétricos}

São denominados VE, todos aqueles veículos que, para seu funcionamento, possuem pelo menos um motor que converte a energia elétrica armazenada em baterias em energia mecânica. Os Veículos a Bateria Elétrica, dependem única e exclusivamente da energia armazenada nas baterias para a sua locomoção. Nesse caso, ele é ligado diretamente à rede elétrica para o carregamento. Veículos Elétricos Híbridos Plug-in, VHEP, são movidos a eletricidade ou a gasolina e têm a singularidade de poderem se recarregar através do motor de combustão interna, ao invés de serem carregadas somente pela rede elétrica.

\subsection{Baterias para veículos elétricos}

Especificamente para os VE, há duas tecnologias de bateria que são predominantes, a de Níquel-Hidreto Metálico (NiHM) e a de Li-Ion [1].

As principais características que se deve conhecer a respeito das mesmas, para dimensioná-las e entender o seu funcionamento para esta aplicação, são:

- Capacidade: É a quantidade de corrente por hora que a bateria, ou célula de bateria é capaz de fornecer [Ah];

- DoD: Profundidade de Descarga (PdD), ou Depth of Discharge (DoD). Mede quanto da capacidade total da bateria será utilizado na descarga, é dada pela relação da Capacidade Utilizada pela Capacidade declarada.

\subsection{Determinação da potência disponível na bateria}

A potência disponível para uso nas baterias pode ser determinada conforme a seguinte Equação 2 [4]:

$P_{d}=\frac{\left[E_{a}-(D D+R e s) \times E f f_{v e}\right] \times E f f_{i n v}}{t_{\text {desc }}}$

Onde:

$P_{d} \quad$ Potência disponível [kW]

$\mathrm{E}_{\mathrm{a}} \quad$ Energia armazenada na bateria [kWh]

DD Distância percorrida desde que a bateria foi $100 \%$ carregada $[\mathrm{km}]$

Res Distância reserva na bateria, definida pelo condutor $[\mathrm{km}]$
$E f f_{v e}$ Eficiência do veículo elétrico em $\mathrm{kWh} / \mathrm{km}$

$E f f_{\text {inv }}$ Eficiência do inversor utilizado [adimensional]

$\mathrm{T}_{\text {desc }} \quad$ Tempo de descarga desejado [h]

Para os veículos $100 \%$ elétricos, leva-se em conta a PdD máxima permitida pela bateria, uma vez que se, ultrapassados esses valores, baixa-se drasticamente a vida útil das mesmas. Isso gera a Equação 3 [5].

$P_{d}=\frac{\left[E_{a^{*}} D o D-(D D+R e s) \times E f f_{v e}\right] \times E f f_{i n v}}{t_{\text {desc }}}$

Para os VHEP, não é necessário prever uma reserva na bateria, uma vez que o motor a combustão pode carregar a bateria e/ou movimentar o veículo, dando origem à Equação 4.

$P_{d}=\frac{\left[E_{a^{*}} D o D-(D D) \times E f f_{v e}\right] \times E f f_{i n v}}{t_{\text {desc }}}$

\section{Estudo de caso}

Construiu-se uma ferramenta de simulação capaz de receber como entrada todos os dados relevantes ao cálculo da utilização do VE como uma fonte de compensação de energia, sendo a plataforma escolhida o Excel. A saída informará a economia e tempo de payback do sistema para cada caso.

O Fluxograma 1 representa o funcionamento do simulador.

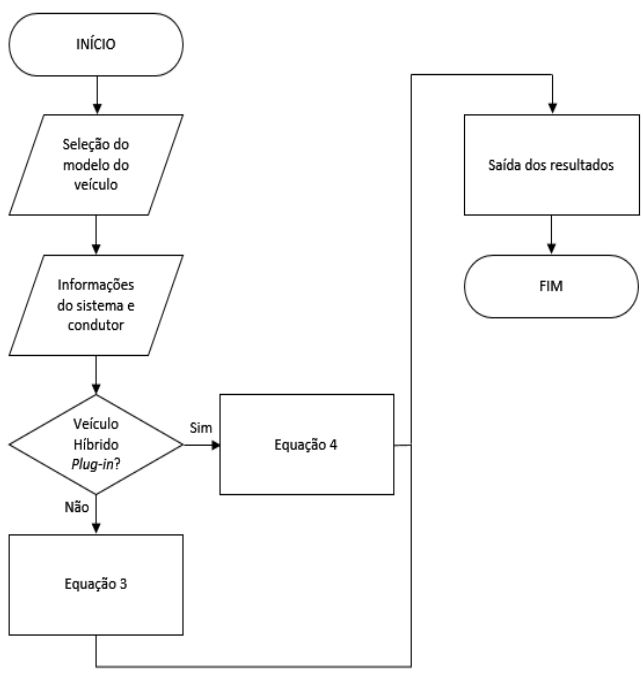

Fluxograma 1. Funcionamento do simulador 
Para a simulação da viabilidade económica, escolheu-se trabalhar com 3 veículos reais e disponíveis no mercado. $O$ Outlander PHEV, um híbrido plug-in da Mitsubishi, e os veículos $100 \%$ elétricos, o Leaf da Nissan e o i3 da BMW.

A tabela 1 contém um sumário das principais características elétricas dos modelos escolhidos para se efetuar a simulação.

\subsection{Custo do sistema}

Sabe-se que o brasileiro troca de carro a cada 1,7 anos. Para Portugal, estimou-se cerca de 3 [1].

Como as baterias que equipam os veículos elétricos têm uma vida útil na ordem de 2000 a 3000 ciclos, ou seja, de no mínimo 5 anos (2000 $\div 365=5,47$ anos) [8], os seus custos de depreciação foram desprezados, uma vez que o período de troca de um veículo usado por um novo é menor do que a vida útil da sua bateria.

Desprezou-se também o preço do VE, assumindo-se que o condutor já possui veículo na sua residência, e não que o compre exclusivamente para compensação.

Compõe o custo do sistema um carregador e um medidor de energia bidirecionais, para ligação à rede e controlo da carga/descarga da bateria, somando um valor estimado de $€ 426$.

\subsection{Hábitos de condução do consumidor português}

A primeira simulação foi feita com base nos hábitos de condução de um condutor médio português.

Constatou-se que o cidadão comum cobre diariamente, uma distância de 45 km [3]. Para a distância de reserva que será mantida na bateria, utilizou-se um valor de $15 \%$ da autonomia total do veículo. O tempo de descarga da bateria para compensação de energia será fixado em 2,5h, para aproveitar o intervalo do horário de ponta na sua totalidade. Obteve-se os resultados demonstrados na Tabela 2.

\begin{tabular}{|c|c|c|c|c|}
\hline Geral & Montadora & Mitsubishi & Nissan & BMW \\
\hline & Veiculo & $\begin{array}{c}\text { Outlander } \\
\text { PHEV }\end{array}$ & Leaf & i3 \\
\hline & Tecnologia & PHEV & $\begin{array}{c}100 \% \\
\text { EV }\end{array}$ & $\begin{array}{c}100 \% \\
\text { EV }\end{array}$ \\
\hline Payback & $\begin{array}{c}\text { t payback } \\
\text { (anos) }\end{array}$ & 8,59 & 0,93 & 1,13 \\
\hline
\end{tabular}

Tabela 2. Tempo de payback por veículo

Verificou-se que o sistema é economicamente viável para aqueles que possuem veículos $100 \%$ elétricos, cujo tempo de payback fica em torno de um ano. Após esse período o utilizador começará a ter lucro efetivamente.

Para os VHEP, o retorno financeiro pode chegar a quase 9 anos, devido ao facto das suas baterias serem de muito menor capacidade que a dos veículos $100 \%$ elétricos.

\begin{tabular}{|c|c|c|c|c|}
\hline \multirow{3}{*}{ Geral } & Montadora & Mitsubishi & Nissan & BMW \\
\hline & Veículo & Outlander PHEV & Leaf & 13 \\
\hline & Tecnologia & PHEV & $100 \% \mathrm{EV}$ & $100 \%$ EV \\
\hline \multirow{4}{*}{ Bateria } & Tecnologia da Bateria & íões de Lítio & í̃es de Lítio & Í̃es de Lítio \\
\hline & Tensão (V) & 300 & 360 & 355,2 \\
\hline & Capacidade (Ah) & 40 & 66,67 & 60,81 \\
\hline & Energia (kWh) & 12 & 24 & 21,6 \\
\hline \multirow{2}{*}{ Veículo } & Autonomia EV (km) & 52 & 199 & 160 \\
\hline & Eficiência (kWh/100km) & 18,46 & 9,65 & 10,8 \\
\hline
\end{tabular}

Tabela 1. Principais características dos veículos híbridos e elétricos 
Nesse caso, a utilização do VHEP seria vantajosa apenas para uso do veículo como um nobreak, no caso de uma falha elétrica da rede ou de algum equipamento interno à instalação do cliente.

\subsection{Diferentes perfis de condução}

Para diferentes perfis de condução foi analisado qual VE, de entre os modelos de veículos pré-definidos, terá o menor tempo de payback e maiores lucros aos utilizadores.

Para tal, variou-se de 0 a $50 \mathrm{~km}$ a distância percorrida diariamente, utilizando-se um passo de $10 \mathrm{~km}$. Para cada uma dessas distâncias variou-se também a distância de reserva de 0 a $30 \mathrm{~km}$, com o mesmo passo de $10 \mathrm{~km}$.

Será considerado rentável apenas aqueles casos em que o payback do sistema se dê em menos de 3 anos, ou seja, antes que o utilizador troque de veículo.

Os resultados foram compilados em diferentes tabelas. A Tabela 3 é referente ao Nissan Leaf.
A terceira coluna mostra a energia da bateria que está disponível para utilização na residência e a quarta informa de quanto será a economia bruta anual do usuário.

Por último está o tempo de payback do sistema. Mais uma vez foi considerado viável aqueles casos em que esse valor seja menor que 3 anos.

Para os VHEP é óbvio que a distância de reserva não afeta o tempo de payback do sistema, uma vez que pelo facto de possuir um motor a combustão, assume-se que nunca faltará gasolina em períodos de emergência, portanto não se deve constituir reserva da bateria. Os perfis vantajosos são aqueles que percorrem até $30 \mathrm{~km}$ diários, ou seja, do A ao I.

Já para os veículos elétricos, observa-se que quanto menor a soma das distâncias percorrida e reserva, menor o tempo necessário para payback. Para ambos modelos, o Leaf e o i3, independente da distância percorrida e da distância de reserva os veículos são recomendáveis, com payback dentro dos limites estabelecidos neste trabalho.

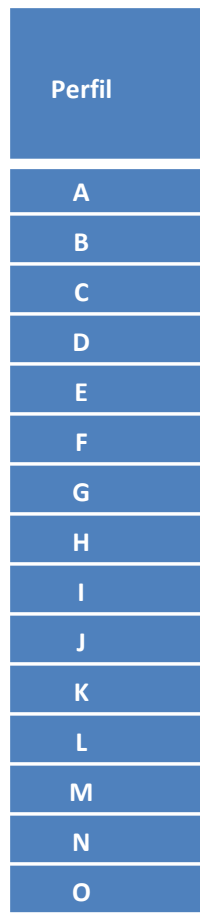

\begin{tabular}{|c|}
\hline Distância \\
Percorrida \\
\hline 10 \\
\hline 10 \\
\hline 10 \\
\hline 20 \\
\hline 20 \\
\hline 20 \\
\hline 30 \\
\hline 30 \\
\hline 30 \\
\hline 40 \\
\hline 40 \\
\hline 40 \\
\hline 50 \\
\hline 50 \\
\hline 50 \\
\hline
\end{tabular}

\begin{tabular}{|l|}
\hline Reserva \\
\hline 10 \\
\hline 20 \\
\hline 30 \\
\hline 10 \\
\hline 20 \\
\hline 30 \\
\hline 10 \\
\hline 20 \\
\hline 30 \\
\hline 10 \\
\hline 20 \\
\hline 30 \\
\hline 10 \\
\hline 20 \\
\hline 30 \\
\hline
\end{tabular}

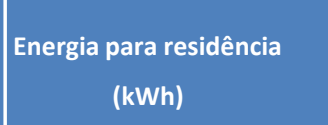

\begin{tabular}{|c|c|}
\hline $\begin{array}{c}\text { Economia bruta anual } \\
\text { (EUR) }\end{array}$ & Payback \\
\hline 662,40 & 0,64 \\
\hline 625,40 & 0,68 \\
\hline 588,39 & 0,72 \\
\hline 625,40 & 0,68 \\
\hline 588,39 & 0,72 \\
\hline 551,39 & 0,77 \\
\hline 588,39 & 0,72 \\
\hline 551,39 & 0,77 \\
\hline 514,38 & 0,83 \\
\hline 551,39 & 0,77 \\
\hline 514,38 & 0,83 \\
\hline 477,37 & 0,89 \\
\hline 514,38 & 0,83 \\
\hline 477,37 & 0,89 \\
\hline 440,37 & 0,97 \\
\hline & \\
\hline
\end{tabular}

Tabela 3. Tempo de payback para diferentes perfis de condução - Nissan Leaf 


\subsection{Energia mínima da bateria para o utilizador}

Para a última simulação variou-se a energia da bateria de forma a se obter um tempo de payback exato de 3 anos, obtendo a capacidade mínima da bateria para cada tecnologia.

$\mathrm{Na}$ Tabela 4, as quarta e quinta colunas indicam, respetivamente, qual a energia mínima necessária na bateria para cada tecnologia, de acordo com os perfis. Isso é útil, principalmente, para os veículos não mencionados aqui e também os VHEP, que no geral têm capacidades de bateria menores. Dessa forma, o condutor sabe, de acordo com seu perfil, qual a menor energia que a bateria do veículo deve possuir.

\begin{tabular}{|l|l|l|l|l|}
\hline Pe & $\begin{array}{c}\text { Dist. } \\
\text { rfil }\end{array}$ & $\begin{array}{c}\text { Rercorri } \\
\text { se }\end{array}$ & $\begin{array}{c}\text { Energia } \\
\text { mínima } \\
\text { rv }\end{array}$ & $\begin{array}{r}\text { Energia } \\
\text { mínima } \\
\text { Híbrido }\end{array}$ \\
\hline A & 10 & 10 & 7,13 & 6,88 \\
\hline B & 10 & 20 & 8,38 & 6,88 \\
\hline C & 10 & 30 & 9,63 & 6,88 \\
\hline D & 20 & 10 & 8,38 & 9,13 \\
\hline E & 20 & 20 & 9,63 & 9,13 \\
\hline F & 20 & 30 & 10,88 & 9,13 \\
\hline G & 30 & 10 & 9,63 & 11,38 \\
\hline H & 30 & 20 & 10,88 & 11,38 \\
\hline I & 30 & 30 & 12,13 & 11,38 \\
\hline J & 40 & 10 & 10,88 & 13,63 \\
\hline K & 40 & 20 & 12,13 & 13,63 \\
\hline L & 40 & 30 & 13,38 & 13,63 \\
\hline M & 50 & 10 & 12,13 & 15,88 \\
\hline N & 50 & 20 & 13,38 & 15,88 \\
\hline O & 50 & 30 & 14,63 & 15,88 \\
\hline P & 45 & 32 & 14,25 & 14,75 \\
\hline
\end{tabular}

Tabela 4. Capacidade mínima da bateria

\subsection{Resultados e análises dos resultados}

Para o proprietário do veículo elétrico, a vantagem de utilizar o sistema de compensação de energia elétrica no horário de ponta seria a de otimizar o seu consumo de energia proveniente da rede.
Ao final de cada mês, além da economia na fatura de energia elétrica, o condutor teria também uma fonte de renda adicional.

Neste trabalho provou-se que a utilização da bateria de veículos elétricos para alimentar uma residência durante o horário de ponta é economicamente vantajosa. Para o cidadão médio português é obrigatória a utilização de veículos movidos $100 \%$ a energia elétrica para que haja economia percetível na fatura de energia.

Quando se testou outros perfis de condução, os veículos $100 \%$ elétricos continuaram a ser uma opção financeiramente viável. Para os veículos híbridos é importante que o condutor não possua grandes necessidades de deslocamento diário. Para tal, o limite de distância percorrida é de $30 \mathrm{~km}$ para que o payback seja aceitável.

\section{Referências}

[1] ANEEL. Resolução Normativa N 479: Condições Gerais de Fornecimento de Energia Elétrica. [s. L.]: Aneel, 2012. 56 p. Disponível em: <www.aneel.gov.br/cedoc/ren2012479.pdf>.

[2] EDP. Horários Baixa Tensão Normal. 2014. Disponível em: <http://www.edpsu.pt/pt/particulares/tarifasehorarios/ horarios/Pages/HorariosBTN.aspx>. Acesso em: $22 \mathrm{dez}$. 2014.

[3] INFAS. Mobilität in Deutschland 2008: Ergebnisbericht Struktur - Aufkommen - Emissionen - Trends. Berlin: Bundesministeriums Für Verkehr, Bau Und Stadtentwicklung, 2008. Disponível em: $<$ http://www.mobilitaet-indeutschland.de/pdf/MiD2008_Abschlussbericht_I.pdf>.

[4] KEMPTOM, Willett et al. Vehicle-to-Grid Power: Battery, Hybrid, and Fuel Cell Vehicles as Resources for Distributed Eletric Power in California. California: California Air Resources Board And The California Environmental Protection Agency, 2001. 78 p. Disponível em: <www.udel.edu/V2G/docs/V2G-Cal-2001.pdf>. 
[5] MAgALHÃES, Daniel Filipe Pereira. Projeto De Um Sistema De Gestão De Baterias (BMS) Aplicadas $\mathrm{Na}$ Alimentação De Veículos Elétricos (EVs). 2012. $41 \mathrm{f}$. Dissertação (Mestrado em Curso de Engenharia Eletrotécnica e de Computadores Major Automação) Feup, Porto, 2012. Disponível em: $<$ http://paginas.fe.up.pt/ ee05223/wpcontent/uploads/2012/09/dissertação_1926_2012_provi sória.pdf>.

[6] ROSOLEM, Maria de Fátima N. C. et al. Bateria de LítioÍon: Conceitos Básicos e Suas Potencialidades. Saber Eletrônica, São Paulo, v. 48, n. 464, p.56-66, set. 2012. Disponível

em: <http://www.sabereletronica.com.br/files/file/SE464_w eb.pdf>.
[7] TELEFONICA. Connected Car Industry Report 2014. London, $2014 . \quad$ Disponível em: $<$ http://blog.digital.telefonica.com/wpcontent/uploads/2014/07/TelefonicaConnected_Car_Report_2014-Final-en.pdf>.

[8] WITTMANN, D; BERMANN, C; WITTMANN, T F. Análise Crítica da Integração em Larga Escala de Veículos Elétricos no Brasil. In: INTERNATIONAL WORKSHOP ADVANCES IN CLEANER PRODUCTION, 4., 2013, São Paulo. Proceedings... . São Paulo: International Workshop Advances In Cleaner Production, 2013. p. 1 - 10. Disponível

em: <http://www.abve.org.br/downloads/Artigo - Análise Crítica da Integração em Larga Escala de Veículos Elétricos no Brasil.pdf>.

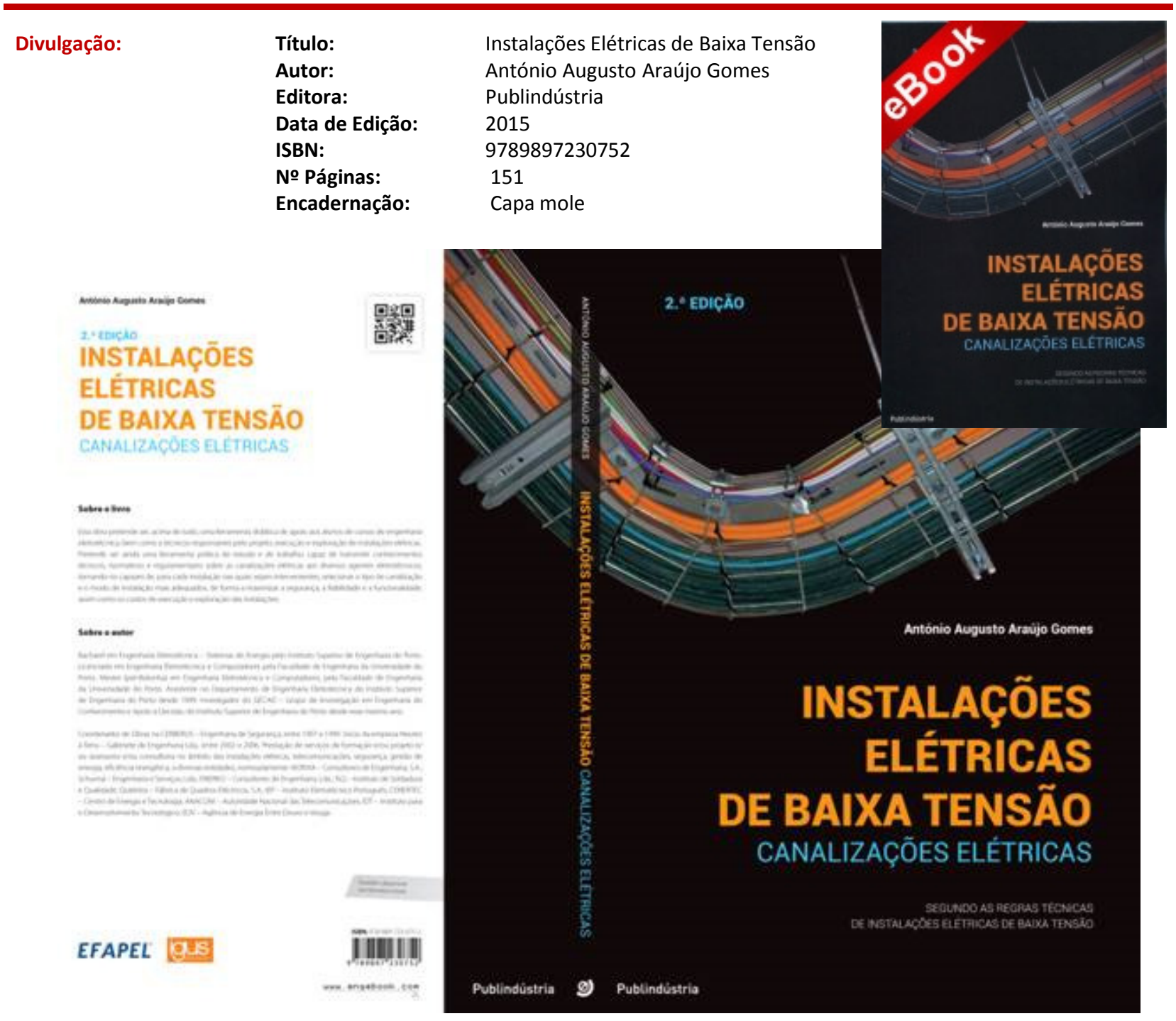

